\title{
Synthesis of Bulk, Dense, Nanocrystalline Yttrium Aluminum Garnet from Amorphous Powders
}

\author{
Pathikumar Sellappan, ${ }^{\dagger}$ Vikram Jayaram, ${ }^{\star}$ and Atul H. Chokshi \\ Department of Materials Engineering, Indian Institute of Science, Bangalore 560012, India
}

Canchi Divakar

Materials Science Division, National Aerospace Laboratories, Bangalore 560017, India

\begin{abstract}
Amorphous powders of $\mathrm{Al}_{2} \mathrm{O}_{3}-37.5 \mathrm{~mol} \% \mathrm{Y}_{2} \mathrm{O}_{3}$ (yttrium aluminum garnet (YAG)) were prepared by coprecipitation, decomposed at $800^{\circ} \mathrm{C}$, and hot-pressed uniaxally at low temperature $\left(600^{\circ} \mathrm{C}\right)$ and a moderate pressure $(750 \mathrm{MPa})$. Optimum conditions yielded microstructures with only $2 \%$ porosity and partial crystallization of YAG. Further processing using high quasihydrostatic pressure $(1 \mathrm{GPa})$ at $1000 \mathrm{C}$ enabled the production of fully crystallized YAG with $>96 \%$ relative density and a nanocrystalline grain size of $\sim 70 \mathrm{~nm}$.
\end{abstract}

\section{Introduction}

Y TTRIUM aluminum garnet (YAG) is one of the most creepresistant single-crystal oxides known at temperatures over $1600^{\circ} \mathrm{C} .^{1,2}$ Being a refractory oxide with low intrinsic diffusivities, the sintering of YAG through conventional routes generally requires temperatures in excess of $1600^{\circ} \mathrm{C}$, leading to grain sizes of several micrometers. Solution routes for making amorphous powders offer the possibility of producing ultra-fine nanostructured materials by an extension of the classical method of devitrifying a glass. Chemical homogeneity is ensured by a molecular level mixing of precursors of aluminum and yttrium at room temperature, ${ }^{3-6}$ while the amorphous phase that follows precursor decomposition has been shown to be capable of being densified in this system ${ }^{7,8}$ as well as, earlier, in the $\mathrm{ZrO}_{2}-\mathrm{Al}_{2} \mathrm{O}_{3}$ system. ${ }^{9,10}$ Densification in $\mathrm{ZrO}_{2}-\mathrm{Al}_{2} \mathrm{O}_{3}{ }^{9,10}$ and in $\mathrm{Al}_{2} \mathrm{O}_{3}$ $15 \% \mathrm{Y}_{2} \mathrm{O}_{3}{ }^{8}$ allows the amorphous phase to be retained and subsequently crystallized in a controlled manner. The unusual densification and deformation behavior of the amorphous phase was attributed partially to the low density of the amorphous phase $(\sim 2 / 3$ of the assemblage of crystalline equilibrium phases), while the ability to retain the amorphous phase during highpressure densification was attributed to the kinetic hindrance to crystallization owing to the need for phase separation ${ }^{7,8}$ and the relatively high associated crystallization temperatures of $700^{\circ}$ $1000^{\circ} \mathrm{C}$, which provide a large window between the hot pressing and devitrification temperatures. ${ }^{4-8,11}$ This large difference in molar volume is also a potential source of porosity during crystallization. Earlier studies of densification of the amorphous stoichiometric composition, $\mathrm{Y}_{3} \mathrm{Al}_{5} \mathrm{O}_{12}$, reported simultaneous crystallization to form nanometric grains of YAG, presumably due to the absence of any need for phase separation and longrange diffusion. ${ }^{7}$ However, it was also discovered that the measured absolute densities $\left(3.32 \mathrm{~g} / \mathrm{cm}^{3}\right)$ of the hot-pressed pellets

M. Cinibulk — contributing editor

\footnotetext{
Manuscript No. 23006. Received March 30, 2007; approved June 6, 2007.

${ }^{*}$ Member of the American Ceramic Society.

Author to whom correspondence should be addressed. e-mail: pathikumar s@a yahoo.co.in
}

were substantially lower than that of the crystalline YAG (4.55 $\left.\mathrm{g} / \mathrm{cm}^{3}\right)$, despite the presence of only $\sim 2 \%$ porosity determined by metallography. These results indicated that crystallization was not complete. Consequently, the present study followed from attempts to produce fully crystalline YAG by a modification of the above route.

It is already reported that the sintering of YAG powders requires several hours in the temperature range of $1650^{\circ}-1750^{\circ} \mathrm{C}$, which led to final grain sizes of $\sim 3-7.5 \mu \mathrm{m} .{ }^{12}$ The present study was undertaken to establish an optimum route to obtain dense, fully crystallized YAG with fine grains at lower temperatures, without additives.

\section{Experimental Procedure}

\section{(1) Preparation of Amorphous Powders}

Amorphous $\mathrm{Al}_{2} \mathrm{O}_{3}-37.5 \mathrm{~mol} \% \mathrm{Y}_{2} \mathrm{O}_{3}$ (YAG) powders were coprecipitated from aqueous nitrate precursor solutions, using ammonia solution as reported earlier. ${ }^{4,8}$ As-dried precipitates were decomposed at $800^{\circ} \mathrm{C}$ for $5 \mathrm{~min}$ at a heating rate of $10^{\circ} \mathrm{C} /$ min to remove volatile matter. Large agglomerates were classified to $\leq 10 \mu \mathrm{m}$ to avoid local densification, as confirmed by laser scattering (Malvern Instruments Ltd. and Microtrac UPA150, Montgomery Ville, PA) before uniaxial hot pressing.

\section{(2) Uniaxial Hot Pressing and Crystallization}

The decomposed, classified, X-ray amorphous powders were uniaxially pressed under $50 \mathrm{MPa}$ pressure for $5 \mathrm{~min}$ at room temperature in a 5-mm-diameter cylindrical nickel-based superalloy die-punch assembly with graphite lubricant and spacers between the powder compact and the punches. The pressure inside the die assembly was increased to $750 \mathrm{MPa}$ and the assembly was heated at a maximum pressure to $600^{\circ} \mathrm{C}$ at $10^{\circ} \mathrm{C} / \mathrm{min}$ and held for $10 \mathrm{~min}$; as noted earlier, this led to partial crystallization.

The above partially crystallized pellets were re-pressed above the crystallization temperature $\left(1000^{\circ}-1200^{\circ} \mathrm{C}\right)$ at a quasihydrostatic pressure of 500-1000 MPa with the objective of retaining the fine microstructure with high density. A high-pressure-high temperature apparatus with tungsten carbide anvils having a semi-spherical cavity with a pyrophyllite gasket was used. ${ }^{13}$ The semi-spherical cavity apparatus with the 600 ton press used in the present experiments is capable of generating 6 $\mathrm{GPa}$ and $2000^{\circ} \mathrm{C}$ with a working volume of $\sim 0.5 \mathrm{~cm}^{3}$. The sample was contained in a graphite tube, which also serves as a heater. Typically, the cell was loaded to $\sim 200 \mathrm{MPa}$ to create a gasket pressure around the pyrophyllite cell, and then heated to $1000^{\circ} \mathrm{C}$ at $35^{\circ} \mathrm{C} / \mathrm{min}$. For all the experiments, load was applied from $\sim 700^{\circ} \mathrm{C}$ and it reached a maximum at $\sim 1 \mathrm{GPa}$ before $\sim 900^{\circ} \mathrm{C}$. The pressure and temperature conditions were 
maintained for $10 \mathrm{~min}$, and after the experiments, the temperature and load were reduced simultaneously.

\section{(3) Characterization}

Thermogravimetric (TG) and differential thermal analysis (DTA) were performed on as-dried powder as well as on pellets pressed uniaxially and quasi-hydrostatically at a heating rate of $10^{\circ} \mathrm{C} / \mathrm{min}$ in air (SDT Q600-TA Instruments, New Castle, $\mathrm{DE})$ to determine the temperatures of decomposition and crystallization. X-ray diffraction (XRD, $\mathrm{Cu} K \alpha$, JEOL JDX-8030, Tokyo, Japan) was used to examine phase evolution. The true density of the powder was measured by pycnometry with specific gravity bottles of $10 \mathrm{~mL}$ volume and deionized water as the fluid medium, after removing hard agglomerates and allowing 20-25 days to achieve full infiltration of the finest interparticle voids. The densities of the hot-pressed samples were measured by the Archimedes method using boiling water (ASTM C373), and sample porosity was calculated by image analysis of the polished surface using scanning electron microscopy (Sirion, FEI, Hillsboro, OR). Transmission electron microscopy (TEM, Tecnai, G-F30, Hillsboro, OR) was performed after ion milling (PIPS, Gatan, 691, Pleasanton, CA). Nanoindentation studies (minimum 10 indentations per load) were carried out taking care to avoid any residual pores using a Berkovich diamond indenter (Triboindenter, Hysitron Inc., Minneapolis, MN) with a nominal tip radius of $100 \mathrm{~nm}$ and maximum loads of $0.3-50 \mathrm{mN}$. The maximum load was held for $10 \mathrm{~s}$ to allow for thermal drift corrections.

\section{Results and Discussion}

\section{(1) Powder Characteristics}

In the DTA curves of the powder, shown in Fig. 1, the exothermic peak at $930^{\circ} \mathrm{C}$ comes from the crystallization of YAG. The as-dried coprecipitated powder was X-ray amorphous up to $800^{\circ} \mathrm{C}$ (Fig. 2). The true densities of the decomposed powder were found to be $3.08 \mathrm{~g} / \mathrm{cm}^{3}$, which is similar to that of the spray-pyrolyzed powder reported earlier ${ }^{7}$ and is about $2 / 3$ of the value of $4.55 \mathrm{~g} / \mathrm{cm}^{3}$ for the equilibrium YAG.

\section{(2) Hot Pressing of the Amorphous Powders}

The coprecipitated amorphous powder was hot pressed at $600^{\circ} \mathrm{C}$ and $750 \mathrm{MPa}$. As in the case of the spray pyrolyzed powder, ${ }^{7}$ the present powder could also be consolidated to relatively high densities with a porosity of $\sim 2 \%$ from image analysis of the polished surface. XRD pattern of the as-hot-pressed pellet (Fig. 2) indicates the crystallization of pure YAG during consolidation. However, the absolute density of the bulk material

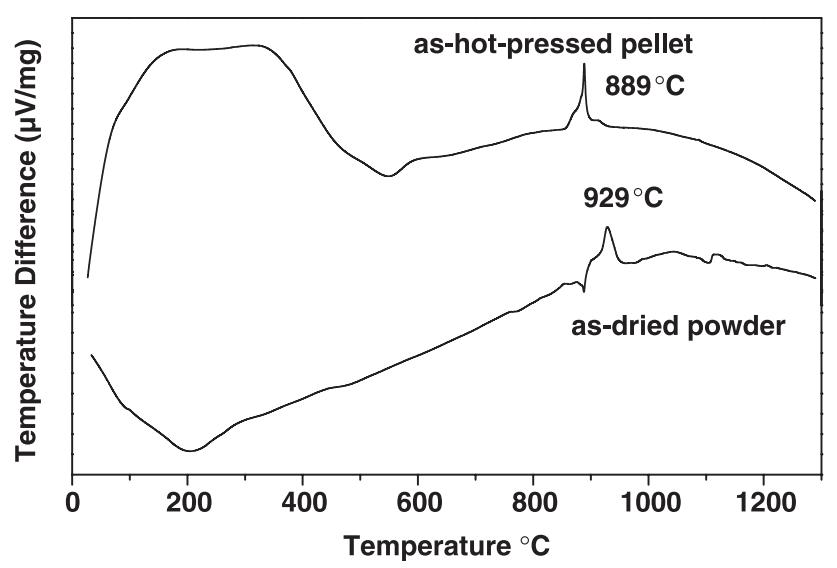

Fig. 1. Differential thermal analysis curves of the as-dried powder and as-hot-pressed pellet at $600^{\circ} \mathrm{C}$ under $750 \mathrm{MPa}$ for $10 \mathrm{~min}$. Note that the exothermic peak for crystallization of yttrium aluminum garnet at $890^{\circ}-$ $930^{\circ} \mathrm{C}$ is also seen from the hot-pressed pellet.

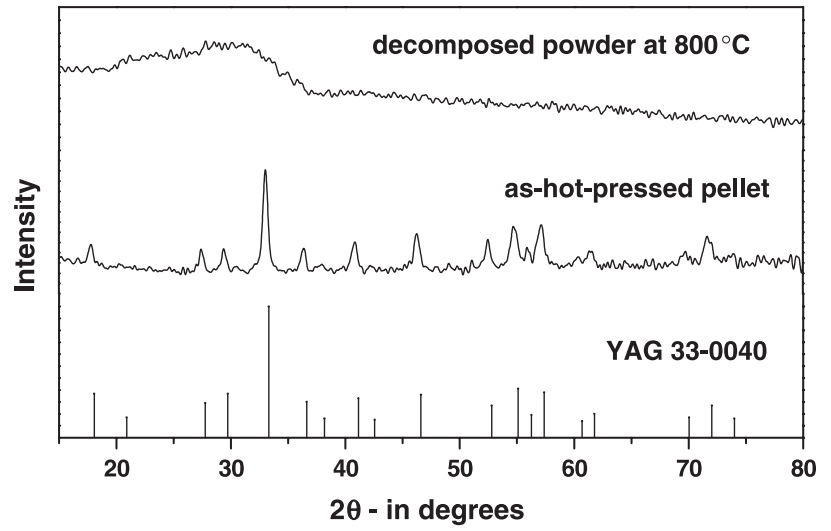

Fig. 2. X-ray diffraction patterns of the decomposed coprecipitated powder, the as-hot-pressed pellet and the standard for yttrium aluminum garnet (YAG) (JCPDS 33-0040). Partial crystallization to YAG is seen, at least $200^{\circ} \mathrm{C}$ below the onset seen by differential thermal analysis, presumably due to the high pressures involved.

was measured to be $3.32 \mathrm{~g} / \mathrm{cm}^{3}$, indicating that a substantial fraction of the pellet was still amorphous. The retention of an amorphous phase in the as-hot-pressed pellet is confirmed by the persistence of the exotherm in DTA at $890^{\circ} \mathrm{C}$ (Fig. 1). Knowing the densities of the amorphous phase and of YAG, one can estimate that $\sim 17 \%$ of the material has crystallized during hot pressing, which is not inconsistent with the ratio of the areas under the DTA exotherms in the two samples. The crystallite size from XRD using Scherer's formula was $\sim 16 \mathrm{~nm}$, which is confirmed from TEM bright-field images shown in Fig. 3. Nano YAG crystals appear, when at the diffracting condition, as dark regions in the amorphous matrix. The latter may be identified by the relative absence of contrast change upon tilting, as illustrated by region $\mathrm{A}$, while the crystallites appear and disappear (region $\mathrm{G}$ ).

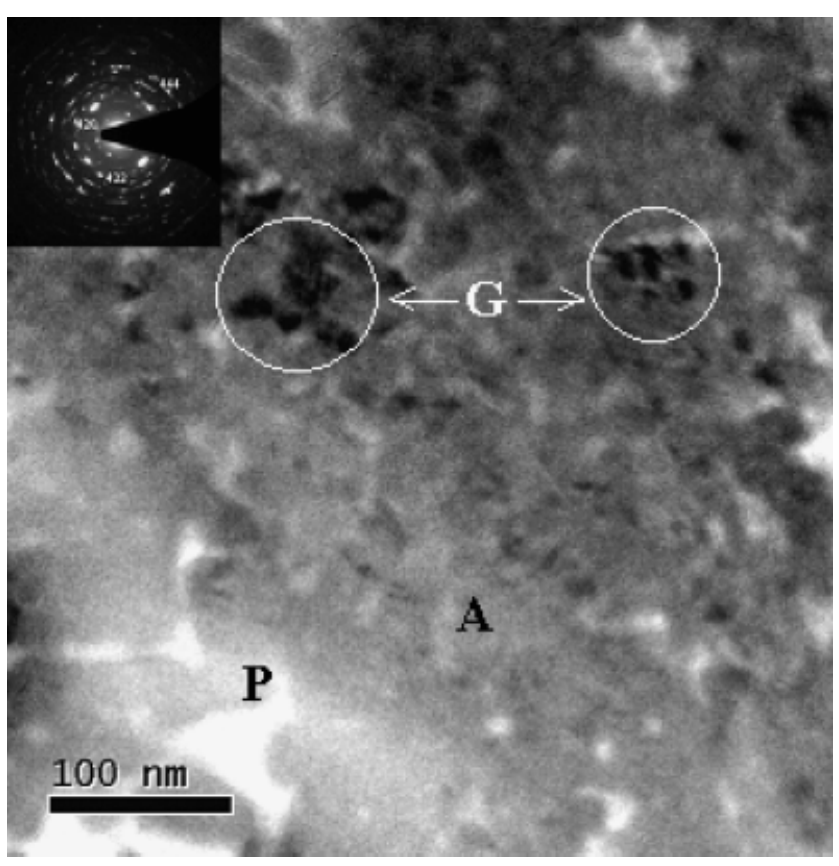

Fig. 3. Bright-field transmission electron microscopic image of the partially crystallized as-hot-pressed pellet $\left(600^{\circ} \mathrm{C}, 750 \mathrm{MPa}\right.$ for $\left.10 \mathrm{~min}\right)$ shows yttrium aluminum garnet (YAG) nano crystals $(\mathrm{G})$ randomly distributed in an amorphous matrix (A). The diffraction rings in the inset may be indexed to YAG. Note: the crystallites $(\mathrm{G})$ change contrast with tilt, the amorphous matrix $(\mathrm{A})$ and pores $(\mathrm{P})$ do not. 


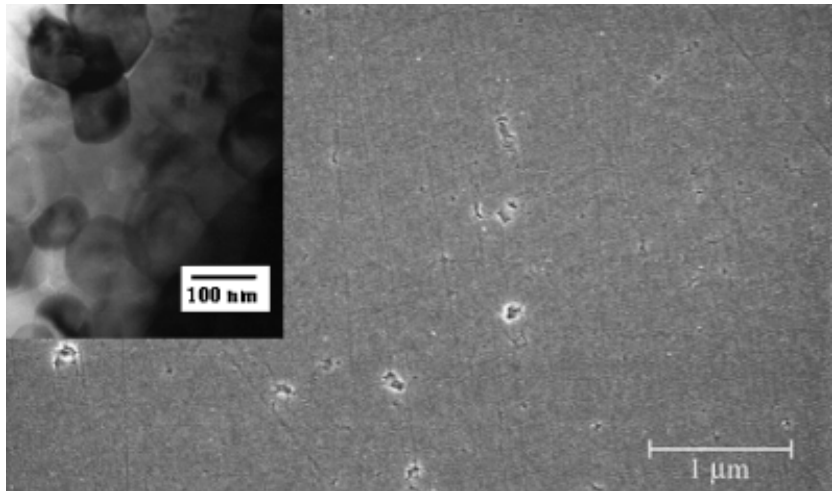

Fig. 4. Scanning electron microscopic image of yttrium aluminum garnet (YAG) crystallized at $1000^{\circ} \mathrm{C}, 1 \mathrm{GPa}$ showing fine pores. Inset shows a transmission electron microscopic image revealing $\sim 50-100 \mathrm{~nm}$ grains.

\section{(3) Crystallization Under High Pressure-High Temperature}

Before the high-quasi-hydrostatic pressure experiment, the ashot-pressed pellet was heat treated well above the crystallization temperature between $1100^{\circ}$ and $1400^{\circ} \mathrm{C}$. However, crystallization resulted in densities of only up to $\sim 4.02 \mathrm{~g} / \mathrm{cm}^{3}(88 \%$ of the YAG theoretical density), as measured by the Archimedes principle, as a result of the large molar volume shrinkage associated with the transformation. The pores caused during crystallization could not be eliminated by sinter forging, vacuum hot pressing, or even by spark plasma sintering at temperatures up to $1400^{\circ} \mathrm{C}$ with pressures $\sim 100 \mathrm{MPa}$.

After consolidation under high-quasi-hydrostatic pressure, a relative density of $95 \%-96 \%$ of YAG was obtained either at 590 $\mathrm{MPa}$ and $1200^{\circ} \mathrm{C}$ or at $1 \mathrm{GPa}$ and $1000^{\circ} \mathrm{C}$. The structure at $1000^{\circ} \mathrm{C}$ may be seen in Figs. 4 and 5 with fine, evenly distributed porosity and mean grain sizes $\sim 70 \mathrm{~nm}$ (Fig. 4). High-resolution lattice images (Fig. 5) show grain boundaries that are free of amorphous phase to within $\sim 0.5 \mathrm{~nm}$ resolution. The DTA curve of the crystallized pellet confirms the absence of amorphous phase (not shown here).

Nano-indentation studies (Table I) reveal that the hardness and elastic modulus rise, respectively, from $\sim 11.5$ and $160 \mathrm{GPa}$ in the partially crystallized (uniaxially pressed) material to

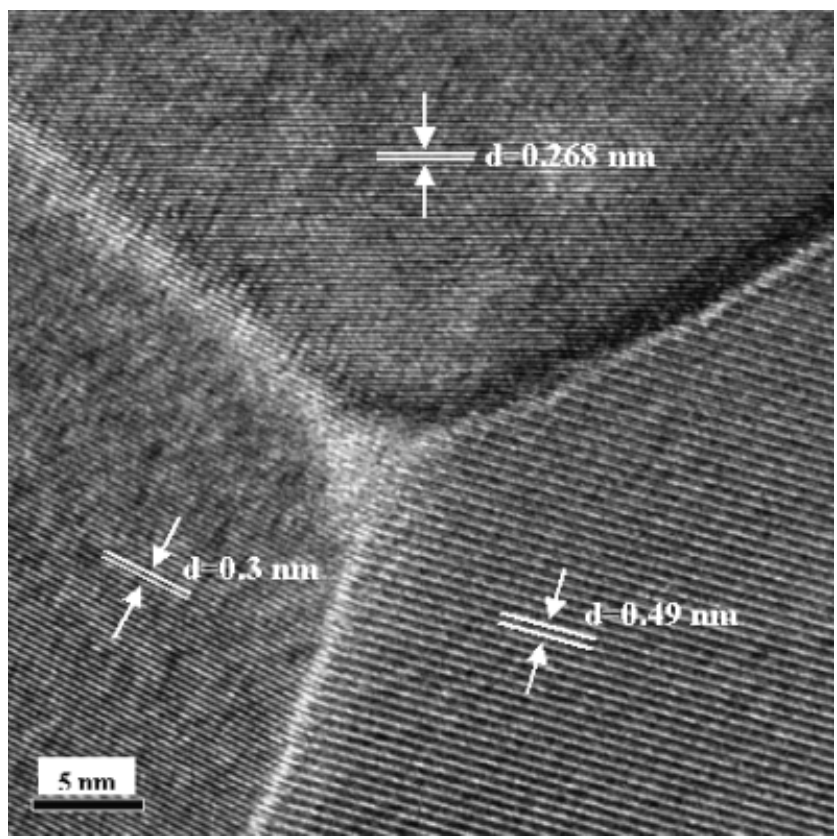

Fig. 5. Lattice image of a triple junction of sample in Fig. 4 revealing grain boundaries free of amorphous phase.
Table I. Nano-Indentation Results of the Partially and Fully Crystallized YAG

\begin{tabular}{lcccc}
\hline & $\begin{array}{c}\text { Relative } \\
\text { density } \\
(\%)\end{array}$ & $\begin{array}{c}\text { Absolute } \\
\text { density } \\
\left(\mathrm{g} / \mathrm{cm}^{3}\right)\end{array}$ & $\begin{array}{c}\text { Hardness } \\
(\mathrm{GPa})\end{array}$ & $\begin{array}{c}\text { Elastic } \\
\text { modulus } \\
(\mathrm{GPa})\end{array}$ \\
\hline $\begin{array}{l}\text { Sample } \\
\text { partially crystallized } \\
\text { pellet, hot pressed }\end{array}$ & $>98$ & 3.32 & $11.5 \pm 0.7$ & $160 \pm 11$ \\
$\begin{array}{l}\text { at } 600^{\circ} \mathrm{C} \text { under } \\
750 \mathrm{MPa}\end{array}$ & & & & \\
$\begin{array}{l}\text { Fully crystallized at } \\
1000^{\circ} \mathrm{C} \text { under } 1 \mathrm{GPa}\end{array}$ & $>96$ & 4.37 & $19.9 \pm 1.0$ & $293 \pm 9$ \\
\hline
\end{tabular}

nearly 20 and $300 \mathrm{GPa}$ in the fully crystallized (quasi-hydrostatically re-pressed) pellet. While the latter values are consistent with the lower hardness $(\sim 15 \mathrm{GPa})$ and similar modulus $(284$ $308 \mathrm{GPa}$ ) reported for microcrystalline Nd:YAG, ${ }^{12,14}$ the pronounced decrease in the hardness and modulus of the partially amorphous sample is consistent with the lower ionic packing density displayed by the amorphous phase.

Thus, a combination of moderately high pressures and low temperatures can achieve near-theoretical density in YAG with high hardness and grain sizes less than $100 \mathrm{~nm}$, without sintering aids or nanocrystalline YAG particles. The enhanced densification of the amorphous precursor to YAG appears to be responsible for accelerated sintering; however, high pressures are needed to permit the use of low temperatures, which inhibit grain growth and, possibly, increase the nucleation rate of the crystalline phase.

\section{Conclusions}

A solution precursor route has been used to prepare YAG with $\sim 96 \%$ relative density and a mean grain size of $\sim 75 \mathrm{~nm}$. Densification is initially assisted by plasticity in the amorphous oxide powder. While a partially crystalline material can be made at $600^{\circ} \mathrm{C}$ and at uniaxial pressures of $750 \mathrm{MPa}$, as reported earlier, a fully crystalline dense microstructure was obtained at a quasihydrostatic pressure of $\sim 1 \mathrm{GPa}$ at $1000^{\circ} \mathrm{C}$ or $\sim 500 \mathrm{MPa}$ at $1200^{\circ} \mathrm{C}$.

\section{Acknowledgments}

This work was financially supported by Defence Research and Development Organization, India. The authors thank Mr. Sasidhara for assistance in the hot pressing experiments, Mr. P. M. Jaman, National Aerospace Laboratories, Bangalore, for assistance in the high-pressure experiment, Gas Turbine Research Establishment, Bangalore, for the superalloy stock, Amit Mondal of Icon Analytical for TEM, and Keshab Barai of the Facility for Electron Microscopy, Indian Institute of Science, for SEM.

\section{References}

${ }^{1}$ G. S. Corman, "High-Temperature Creep of Some Single Crystal Oxides," Ceram. Eng. Sci. Proc., 12 [9-10] 1745-66 (1991).

${ }^{2}$ T. A. Parthasarathy, T. Mah, and K. Keller, "High-Temperature Deformation Behavior of Polycrystalline Yttrium Aluminum Garnet (YAG)," Ceram. Eng. Sci. Proc., 12 [9-10] 1767-73 (1991).

${ }^{3}$ N. Matsushita, N. Tsuchiya, and K. Nakatsuka, "Precipitation and Calcination Processes for Yttrium Aluminum Garnet Precursor Synthesized by the Urea Method," J. Am. Ceram. Soc., 82 [8] 1977-84 (1999).

${ }^{4}$ J.-G. Li, T. Ikegami, J.-H. Lee, T. Mori, and Y. Yajima, "Co-Precipitation Synthesis and Sintering of Yttrium Aluminum Garnet (YAG) Powders: The Effect of Precipitant," J. Eur. Ceram. Soc., 20, 2395-405 (2000).

${ }^{5}$ C. K. Ullal, K. R. Balasubramaniam, A. S. Gandhi, and V. Jayaram, "NonEquilibrium Phase Synthesis in $\mathrm{Al}_{2} \mathrm{O}_{3}-\mathrm{Y}_{2} \mathrm{O}_{3}$ by Spray Pyrolysis of Nitrate Precursors," Acta Mater., 49, 2691-9 (2001).

${ }^{6}$ A. S. Gandhi and C. G. Levi, "Phase Selection in Precursor-Derived Yttrium Aluminium Garnet and Related $\mathrm{Al}_{2} \mathrm{O}_{3}-\mathrm{Y}_{2} \mathrm{O}_{3}$ Compositions," J. Mater. Res., 20, 1017-25 (2005).

${ }^{7}$ S. Choudhury, A. S. Gandhi, and V. Jayaram, "Bulk, Dense, Nanocrystalline Yttrium Aluminum Garnet by Consolidation of Amorphous Powders at Low Temperatures and High Pressures," J. Am. Ceram. Soc., 86 [2] 247-51 (2003). 
${ }^{8}$ N. Thangamani, A. S. Gandhi, V. Jayaram, and A. H. Chokshi, "Low-Temperature High-Pressure Consolidation of Amorphous $\mathrm{Al}_{2} \mathrm{O}_{3}-15 \mathrm{~mol} \% \mathrm{Y}_{2} \mathrm{O}_{3}$," J. Am. Ceram. Soc., 88 [10] 2696-701 (2005).

${ }^{9}$ A. S. Gandhi, V. Jayaram, and A. H. Chokshi, "Dense Amorphous ZirconiaAlumina by Low-Temperature Consolidation of Spray-Pyrolyzed Powders," J. Am. Ceram. Soc., 82 [10] 2613-8 (1999).

${ }^{10} \mathrm{~A}$. S. Gandhi and V. Jayaram, "Pressure Consolidation of Amorphous $\mathrm{ZrO}_{2}-\mathrm{Al}_{2} \mathrm{O}_{3}$ by Plastic Deformation of Powders," Acta Mater., 50, 2137-49 (2002).

${ }^{11} \mathrm{~J}$.-G. Li, T. Ikegami, J.-H. Lee, and T. Mori, "Low-Temperature Fabrication of Transparent Yttrium Aluminum Garnet (YAG) Ceramics Without Additives," J. Am. Ceram. Soc., 83 [4] 961-3 (2000).
${ }^{12}$ H. Yagi, T. Yanagitani, T. Numazawa, and K. Ueda, "The Physical Properties of Transparent $\mathrm{Y}_{3} \mathrm{Al}_{5} \mathrm{O}_{12}$ Elastic Modulus at High Temperature and Thermal Conductivity at Low Temperature," Ceram. Int., 33, 711-4 (2007).

${ }^{13}$ L. Rangaraj, V. Narayanaswamy, P. M. Jaman, C. Divakar, and A. K. Singh, "Fabrication of High Pressure-High Temperature Cell Components Using Pyrophyllite Powder," pp. 445-51 in Advances in High Pressure Research in Condensed Matter: Proceedings of the International Conference on Condensed Matter under High Pressures, November 11-15, 1996. Edited by S. K. Sikka, S. C. Gupta, and B.K. Godwal, NISCOM, New Delhi (1997).

${ }^{14}$ L. Mezeix and D. J. Green, "Comparison of the Mechanical Properties of Single Crystal and Polycrystalline Yttrium Aluminum Garnet," Int. J. Appl. Ceram. Technol., 3 [2] 166-76 (2006). 